\title{
Ceramics International
}

journal homepage: www.elsevier.com/locate/ceramint

\section{Synthesis of vaterite $\mathrm{CaCO}_{3}$ as submicron and nanosized particles using inorganic precursors and sucrose in aqueous medium}

\author{
Luis Pérez-Villarejo ${ }^{\mathrm{a}, *}$, Fatah Takabait ${ }^{\mathrm{b}}$, Laila Mahtout ${ }^{\mathrm{b}}$, Bartolomé Carrasco-Hurtado ${ }^{\mathrm{c}}$, \\ Dolores Eliche-Quesada $^{\mathrm{d}}$, Pedro J. Sánchez-Soto ${ }^{\mathrm{e}}$ \\ ${ }^{a}$ Department of Chemical, Environmental and Materials Engineering, Higher Polytechnic School of Linares, University of Jaén, Campus Científico y Tecnológico, Cinturón \\ Sur $s / n, 23700$ Linares, Jaén, Spain \\ ${ }^{\mathrm{b}}$ Laboratoire de Technologie des Materiaux et de Génie des Procédés (LTMGP), Faculté des Sciences Exactes, Université A. Mira-Béjaïa, Terga Ouzemmour, O6000 Béjaïa, \\ Algeria \\ ${ }^{c}$ Department of Graphical Engineering, Design and Projects, Higher Polytechnic School of Linares, University of Jaén, Campus Científico y Tecnológico, Cinturón Sur s/n, \\ 23700 Linares, Jaén, Spain \\ d Department of Chemical, Environmental and Materials Engineering, Higher Polytechnic School of Jaén, University of Jaen, Campus Las Lagunillas s/n, 23071 Jaén, Spain \\ ${ }^{\mathrm{e}}$ Institut of Materials Science of Sevilla, Mix Center CSIC (Spanish National Research Council)-University of Sevilla, cicCartuja Building, c/Américo Vespucio 49, 41092 \\ Isla de La Cartuja, Sevilla, Spain
}

\section{A R T I C L E I N F O}

\section{Keywords:}

Vaterite

Nanoparticles

Sucrose

Solubility

Precipitation

\begin{abstract}
A B S T R A C T
It is reported the synthesis of $\mathrm{CaCO}_{3}$ vaterite as stable nanoparticles and submicron-sized by a simple and relatively rapid procedure. XRD, SEM and FTIR techniques have been used to characterize the precipitated products. The synthesis is based on chemical precipitation of inorganic salt precursors, calcium nitrate tetrahydrate and sodium bicarbonate, and using the disaccharide sucrose as an additive in aqueous medium. The role of the disaccharide sucrose is to control the vaterite precipitation after nucleation and growth. It has been found that an increase in sugar concentration promotes the crystal precipitation of vaterite with spherulitic morphology, as revealed by SEM, and changed the surface of the precipitated particles. There is a significant difference between $\mathrm{CaCO}_{3}$ precipitation in the absence and presence of sucrose. Addition of $0 \%$ of sucrose leads to $83 \%$ of calcite as identified by XRD methods. In contrast, addition of $67 \%$ of sucrose in aqueous medium produces $100 \%$ vaterite. The present results may be useful to provide a quick, simple, inexpensive and novel method for the controlled synthesis of new advanced biomaterials based on vaterite particles without hazardous chemicals and inert atmosphere, with great possibilities for industrial scale production.
\end{abstract}

\section{Introduction}

Calcium carbonate $\left(\mathrm{CaCO}_{3}\right)$ exists in six different polymorphs: amorphous calcium carbonate, calcium carbonate hexahydrate, calcium carbonate monohydrate, vaterite, aragonite and calcite, where the thermodynamic stability increases in this sequence [1-7]. Amorphous calcium carbonate usually contains $15 \%$ water, being considered the precursor of more thermodynamically stable $\mathrm{CaCO}_{3}$, and aragonite and calcite the most commonly found polymorphs in natural systems [1,4-9]. At normal temperature and pressure conditions (ambient conditions at the surface of earth), the unstable vaterite quickly turns into calcite, which makes their rarity in nature [9]. However, vaterite exists in some sediments, mineral springs and some biological tissues [10]. For instance, vaterite is found in otoliths, freshwater pearls, healed scars of some mollusc shells, gallstones and urinary calculi
$[6,10,11]$. Some impurities, such as metal ions and organic molecules, may stabilize less stable vaterite polymorph and prevent its transformation into calcite or aragonite [6].

Vaterite has a higher solubility than calcite and aragonite and transforms to calcite or aragonite once it is exposed to water $[9,12]$. It should be noted that Cole and Krone [13] found vaterite in mortars and in calcium silicate hydrate on their carbonation (reaction with $\mathrm{CO}_{2}$ ) formed in the hydration-carbonation steps. This polymorph may develop in bonding mortars of marble inlays and high lime hydrogel with time in a hot climate enhanced by the presence of combustion gases [14] and Portland cements [15]. Vaterite has spherical shape and porous inner structure, with diameter of particles ranging from $0.05 \mu \mathrm{m}$ to $5 \mu \mathrm{m}$ [6]. A series of SEM images of artificial carbonate nanostructures, showing highly monodisperse vaterite $\mathrm{CaCO}_{3}$ microspheres and the shape variations (using water or DMF in solution) has been

\footnotetext{
* Corresponding author

E-mail address: lperezvi@ujaen.es (L. Pérez-Villarejo).
} 
reported by Yao et al. [16]. Vaterite has interesting properties such as biodegradability, relative low cost, high surface area, low density and singular physical and chemical properties [6,16-19]. These features make this $\mathrm{CaCO}_{3}$ polymorph a relevant material in biomedicine for various biomedical applications, especially as a new system for encapsulation, transportation and controlled release of molecules of therapeutic interest (drug delivery), personal care applications, preparation of biomaterials and bone implants, as well as some industrial applications like filler in the plastic and paper industries, abrasives, cleaners and adsorbents [6,19-22]. Boyjoo et al. [19] have reported a review paper on synthesis of micro and nano-sized calcium carbonate particles and their applications. In particular, Trushina et al. [6] performed a review paper on vaterite microparticles for biomedical and personal care applications. Consequently, efficient methods to synthesize and stabilize the crystal polymorph of vaterite in pure form and by simple synthetic ways are highly wanted. Several papers report on methods, reaction parameters and synthesis conditions favouring vaterite precipitation including precipitation in aqueous phase [16-19,23,24], and the use of emulsions or techniques of sonication [25-27]. Several factors, such as the presence of organic or inorganic additives, the solvent, temperature, influence of stirring, $\mathrm{pH}$ of the medium and ionic concentration have considerable influence on the process of crystal formation (nucleation and growth), affecting the shape and size of the vaterite particles $[6,16,19,28-33]$. According to a recent review [19], the main synthesis methods of $\mathrm{CaCO}_{3}$ particles are biomimetic synthesis and $\mathrm{CO}_{2}$ bubbling methods. The third one use organic compounds which act "as templates or growth modifiers as well as other physiological parameters" [19], being the main method for industrial scale production. These authors [19] concluded that the synthesis of $\mathrm{CaCO}_{3}$ (micro and nanoparticles) is a field that continues to grow with the aim to provide simple and efficient methods for the controlled production of different sizes, polymorphs and morphologies at the industrial scale. Biomimetic synthesis is divided into two approaches (Table 1). In relation with this method, nacre (also known as mother of pearl) is an organic-inorganic composite material $[16,29]$. It is composed of a large fraction of inorganic minerals, typically $\mathrm{CaCO}_{3}$, and a small fraction of organic biopolymers and inspired by nacre, the synthesis, fabrication and applications of artificial carbonate nanocrystals and layered structural nanocomposites have been reviewed [16]. Thus, the rigid biological systems are increasingly becoming a source of inspiration for the fabrication of next generation of advanced functional materials.

Precipitation of vaterite was successfully achieved in ethylene glycol (EG) affording hollow microspheres of $800 \mathrm{~nm} \pm 100 \mathrm{~nm}$ diameter after the reaction of calcium acetate with $\mathrm{NaHCO}_{3}$ [30]. Nanospheres of vaterite ranging in size between $20 \mathrm{~nm}$ and $430 \mathrm{~nm}$ were also synthesized [31,32]. The role of EG in these methods was the reduction of both the solubility and the rate of crystal growth of calcium carbonate particles. Non-agglomerated vaterite as nanoparticles $(20-60 \mathrm{~nm}$ size) can be synthesized by short-term ultrasonic heating of calcium bicarbonate [31]. On the other hand, Yao et al. [33] have studied the

Table 1

Summary of synthesis methods of $\mathrm{CaCO}_{3}$ particles, based on a previous review. [23] .

\begin{tabular}{ll}
\hline (A) Biomimetic synthesis & $\begin{array}{l}\text { (B) Carbon dioxide } \\
\text { bubbling methods }\end{array}$ \\
\hline $\begin{array}{c}\text { Amorphous calcium carbonate, vaterite, aragonite } \\
\text { and calcite, or a mixture can be synthesized }\end{array}$ & $\begin{array}{l}\text { Calcite is the main } \\
\text { synthesized polymorph } \\
\text { Main method for }\end{array}$ \\
$\begin{array}{c}\text { (1) Precipitation methods: } \\
\text { (a) the spontaneous precipitation reaction } \\
\text { (b) the slow carbonation reaction }\end{array}$ & $\begin{array}{l}\text { production } \\
\text { (2) The reverse emulsion method }\end{array}$ \\
$\begin{array}{c}\text { Applications: a wide range of applications, including } \\
\text { bone grafting, protein immobilisation, catalysis, } \\
\text { biosensors, } \mathrm{CO}_{2} \text { capture, drug delivery vehicles }\end{array}$ & $\begin{array}{l}\text { Applications: filler for } \\
\text { paper, coatings an } \\
\text { polymers }\end{array}$ \\
\hline
\end{tabular}

influence of different concentrations of disaccharide sucrose and bovine serum albumin on the biomimetic crystallization of $\mathrm{CaCO}_{3}$. They found that incubation with $20 \%$ sucrose for seven days promotes the preferred formation of vaterite with respect to calcite. However, the effect of additives on the $\mathrm{CaCO}_{3}$ crystallization mechanism remains yet unknown. In a previous work [34] early attempts at vaterite synthesis were successful.

The purpose of this work was to synthesize and stabilize pure submicrometer-size and nanoparticles of vaterite, examining the morphological changes of the crystals formed by precipitation of inorganic salt precursors in water solution. The disaccharide sucrose was used, as an additive, to control the vaterite precipitation (after nucleation and growth). It is considered a novel method to synthesize stable vaterite particles with spherulitic morphology. The new method presented here is relatively easy, inexpensive, and no hazardous chemicals or inert atmosphere are required, with great possibilities for industrial scale production of vaterite polymorph. The effect of sucrose on the plausible mechanism of $\mathrm{CaCO}_{3}$ formation was mainly focused on the behaviour of hydroxyl groups of the sugar that prevent the dissolution of preformed nuclei and stabilize the nanocrystals of vaterite with spherical shape.

\section{Materials and methods}

Two inorganic salts were used as received: calcium nitrate tetrahydrate $\left[\mathrm{Ca}\left(\mathrm{NO}_{3}\right)_{2} 4 \mathrm{H}_{2} \mathrm{O}\right]$ and sodium bicarbonate $\left(\mathrm{NaHCO}_{3}\right)$, both chemical reagents of analytical grade (Panreac, Barcelona, Spain). As source of sucrose $\left(\mathrm{C}_{12} \mathrm{H}_{22} \mathrm{O}_{11}\right)$, an industrial product was used. The molecule of sucrose, a disaccharide, is formed by 1 molecule of Glucose and 1 molecule of Fructose. Chemically is O- $\alpha$-D-glucopyranosyl-(1-2)$\beta$-D-Fructofuranoside, a compound which is very soluble in water. The industrial product is presented in liquid form, composed of purified water obtained by reverse osmosis and pure sucrose, showing a density of $1.32-1.34 \mathrm{~g} / \mathrm{mL}$. The concentration of sucrose in solution was determined and the value was $67 \mathrm{wt} \%$. This product was obtained by a proprietary procedure using sugar beet at the company Cevital (Algeria).

The initial $1 \mathrm{M}$ solutions of calcium and sodium inorganic salts were prepared in two separate glass beakers. Then, a series of liquid sugar volumes $(0,10,20,30,40$ and $50 \mathrm{~mL})$ was added successively to the two solutions and the final volume was adjusted in all cases to $50 \mathrm{~mL}$ with pure distilled water. The two solutions were mixed directly in a larger glass beaker, used as chemical reactor in air atmosphere, at $30{ }^{\circ} \mathrm{C} \pm 0.1{ }^{\circ} \mathrm{C}$ using a thermostatic bath. The resultant solution was then stirred at $800 \mathrm{rpm}$ for $15 \mathrm{~min}$. The solid product of the reaction was filtered, washed with distilled water and finally dried at $103^{\circ} \mathrm{C} \pm 1{ }^{\circ} \mathrm{C}$.

For the characterization of the crystalline solid phases, vaterite and calcite, X-ray powder diffraction (XRD) of ground powdered samples was performed using a Philips X'Pert PRO Panalytical with Ni-filtered CuKa radiation $(\lambda=1.5418 \AA)$ and graphite monochromator. Quantitative analysis of vaterite and calcite was performed by a previous method of calcium carbonate phase analysis using XRD. Thus, the percentage of each polymorph (vaterite or calcite) of $\mathrm{CaCO}_{3}$ chemical composition was calculated by a formula proposed in the literature of phase analysis using XRD [35].

Fourier transform infra-red (FTIR) spectra obtained using a Shimadzu Corporation IRAffinity-1 equipment were applied using samples pressed with $\mathrm{KBr}$ discs to confirm the characteristic vibration bands of the polymorphs of calcium carbonate. Scanning Electron Microscopy (SEM) was used to study the morphology and textural characteristics of the particles and the images obtained with a Philips ESEM XL-30-TMP-W equipment.

\section{Results and discussion}

The experimental conditions and summary results for precipitation 
Table 2

Experimental conditions and quantitative XRD results of crystalline phases obtained in the experiment series A-F.

\begin{tabular}{|c|c|c|c|c|c|c|}
\hline Experiment & A & B & $\mathrm{C}$ & $\mathrm{D}$ & $\mathrm{E}$ & $\mathrm{F}$ \\
\hline Disaccharide sucrose (\%) & 00.00 & 13.4 & 26.80 & 40.20 & 53.60 & 67 \\
\hline $\begin{array}{l}\mathrm{NaHCO}_{3}(1 \mathrm{M}) \text { and } \mathrm{Ca}\left(\mathrm{NO}_{3}\right)_{2} 4 \mathrm{H}_{2} \mathrm{O} \\
\quad(1 \mathrm{M})\end{array}$ & 0.15 & 0.17 & 0.20 & 0.25 & 0.32 & 0.45 \\
\hline Vaterite $(\%)^{\mathrm{a}}$ & 17 & 83 & 92 & 96 & 98 & 100 \\
\hline Calcite $(\%)^{\mathrm{a}}$ & 83 & 17 & 8 & 4 & 2 & 0 \\
\hline
\end{tabular}

a Determined by quantitative XRD according to a previous procedure [35].

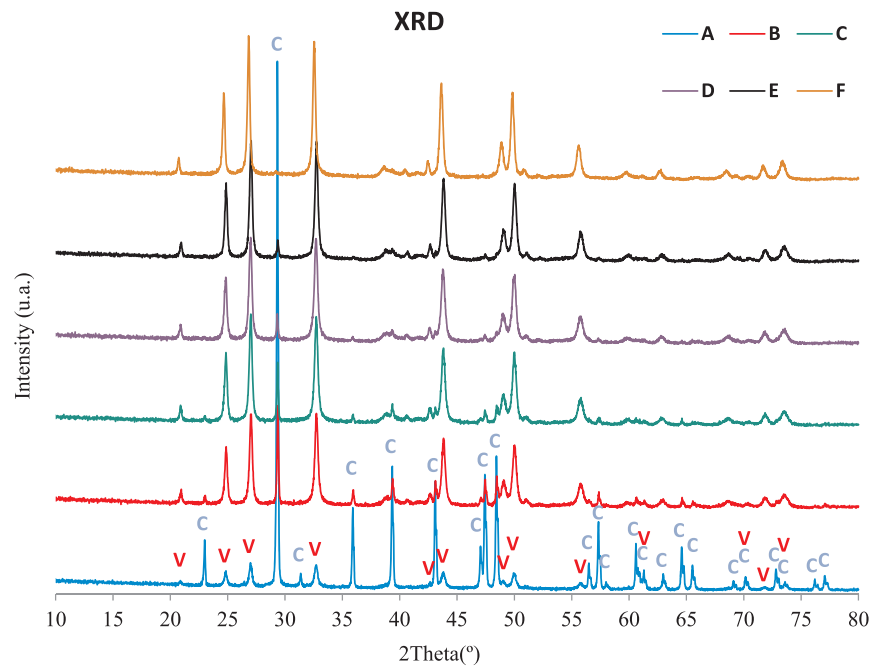

Fig. 1. XRD patterns of precipitated solids in the experiment series A-F in absence and presence of organic additive (sucrose) at different concentrations.

of polymorph crystalline phases of chemical composition $\mathrm{CaCO}_{3}$ at $30{ }^{\circ} \mathrm{C}$ are presented in Table 2. The XRD of the precipitated solids showed the presence of two polymorphs, calcite and vaterite, in varying relative proportions (Fig. 1). Aragonite was not identified and the formation of amorphous calcium carbonate $[6,16]$, if produced, was not observed under the present experimental conditions. Quantitative analysis by XRD (Table 2) indicated that in the absence of sucrose (experiment A), the predominant phase was calcite, with a percentage of $83 \%$ against $17 \%$ of vaterite. The ratio calcite/vaterite abruptly reversed by adding only $13.4 \%$ of sucrose in the solution (or $20 \mathrm{~mL}$ of the water solution of sucrose) in favour of the vaterite precipitation, at a percentage of $83 \%$ against $17 \%$ of calcite (Fig. 1, A and B, and Table 2). In the presence of increasing concentration of sucrose $(26.80 \%$, $40.20 \%, 53.60 \%$ and $67 \%)$ and inorganic salts $(0.20 \mathrm{M}, 0.25 \mathrm{M}, 0.32 \mathrm{M}$ and $0.45 \mathrm{M})$, the characterized crystals revealed the highest relative proportions of the vaterite phase $(92 \%, 96 \%, 98 \%$ and $100 \%)$ and the lowest in the calcite phase $(8 \%, 4 \%, 2 \%$ and $0 \%)$, respectively (Fig. 1C-E). In the case of the solution containing $67 \%$ of sucrose, XRD revealed only peaks corresponding to $100 \mathrm{wt} \%$ vaterite phase, indicating that vaterite was the only polymorph precipitated under these experimental conditions (Fig. 1F).

These results were further confirmed by the corresponding FTIR spectra and analysis of the two polymorphs. Fig. 2 shows the FTIR spectra of the experiment series A-F, being A the experiment without sucrose $(0 \%)$ and $\mathrm{F}$ the experiment using the maximum percentage of sucrose $(67 \%)$ in water solution, following Table 2 . Thus, the absorption bands corresponding to calcite at $713 \mathrm{~cm}^{-1}, 848 \mathrm{~cm}^{-1}$ and $1080 \mathrm{~cm}^{-1}$ are absent in the spectrum of the sample obtained in the presence of $67 \%$ sucrose. Instead, the typical bands of vaterite, located at $744 \mathrm{~cm}^{-1}, 877 \mathrm{~cm}^{-1}$ and $1087 \mathrm{~cm}^{-1}$, attributed to the $\nu 4, \nu 2$ and $\nu 1$ vibrations of $\mathrm{CO}_{3}{ }^{2-}$, respectively, are observed [17,35-38]. Other bands at $3420 \mathrm{~cm}^{-1}$ corresponding to the $\mathrm{O}-\mathrm{H}$ stretching of water and
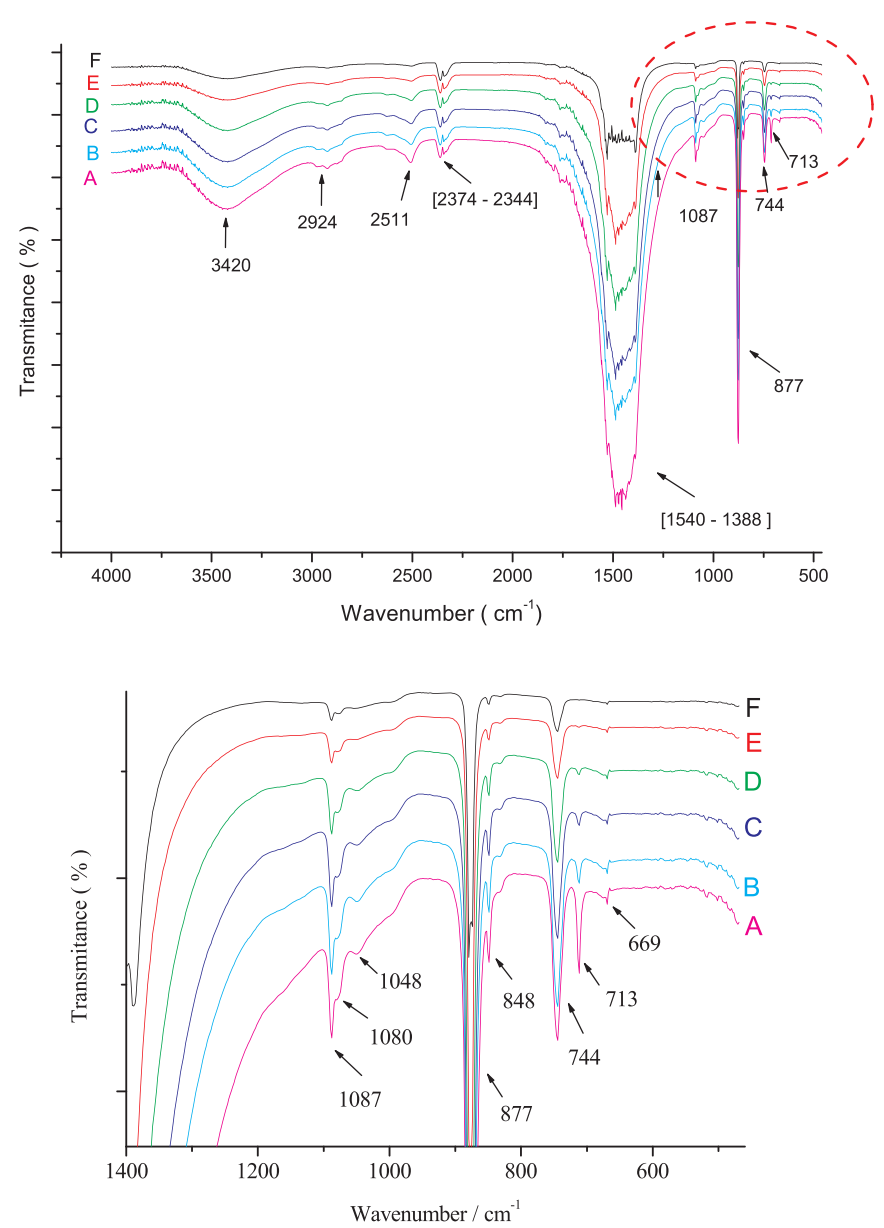

Fig. 2. FTIR spectra of precipitated solid, identified by XRD as a mixture of crystalline vaterite and calcite obtained in absence and presence of organic additive (disaccharide sucrose) at different concentrations.

sucrose, and at $2511 \mathrm{~cm}^{-1}$ and $2924 \mathrm{~cm}^{-1}$, attributed to the C-H stretching of the disaccharide are also present in the spectra [17,35-38]. According to Trushina et al. [6] and other authors, [38] the shifts of peak positions in FTIR spectra indicate interactions between $\mathrm{Ca}^{2+}$ and chemical groups of additional molecules (additives and/or impurities) in the reaction medium. Zhao et al. [30] obtained hollow vaterite microspheres in the $\mathrm{H}_{2} \mathrm{O} / \mathrm{EG}$ system and reported IR bands at $745 \mathrm{~cm}^{-1}, 877 \mathrm{~cm}^{-1}$ and $1084 \mathrm{~cm}^{-1}$ in well agreement with the present results. In the same sense, Fan and Wang [39] investigated the formation of submicrometer-sized vaterite tubes and cups (unusual morphologies) through nanobubble-templated crystal growth of waterelectrolysis-induced mineralization of $\mathrm{CaCO}_{3}$ and reported IR bands of vaterite at $742 \mathrm{~cm}^{-1}, 877 \mathrm{~cm}^{-1}$ and $1080 \mathrm{~cm}^{-1}$.

The changes in the size and morphology studied by SEM of the precipitated solid phases as a function of sucrose concentration are presented in Fig. 3. In absence of the sugar, calcite was clearly observed in rhombohedral form and midsize of $6 \mu \mathrm{m}$, with a low relative proportion of vaterite in spherical (microspheres or spherulitic vaterite) [40] and smooth form with diameter of $\sim 6 \mu \mathrm{m}$. In the presence of sucrose at various concentrations $(13.4 \%, 26.80 \%, 40.20 \%, 53.60 \%$ and $67 \%$ ), the size of the microspheres was reduced. At high sucrose concentration, the proportion of vaterite crystals considerably increased. Many of these crystals become smaller $(1-0.5 \mu \mathrm{m})$ and irregularly shaped with roughness. It is deduced that growth of rhombohedral calcite crystals in co-existence with spherulitic vaterite was gradually inhibited under these experimental conditions and disappeared completely at $67 \mathrm{wt} \%$ sucrose in favour of vaterite. At this proportion of sucrose, vaterite is $>98 \mathrm{wt} \%$. It can be noted that sucrose 


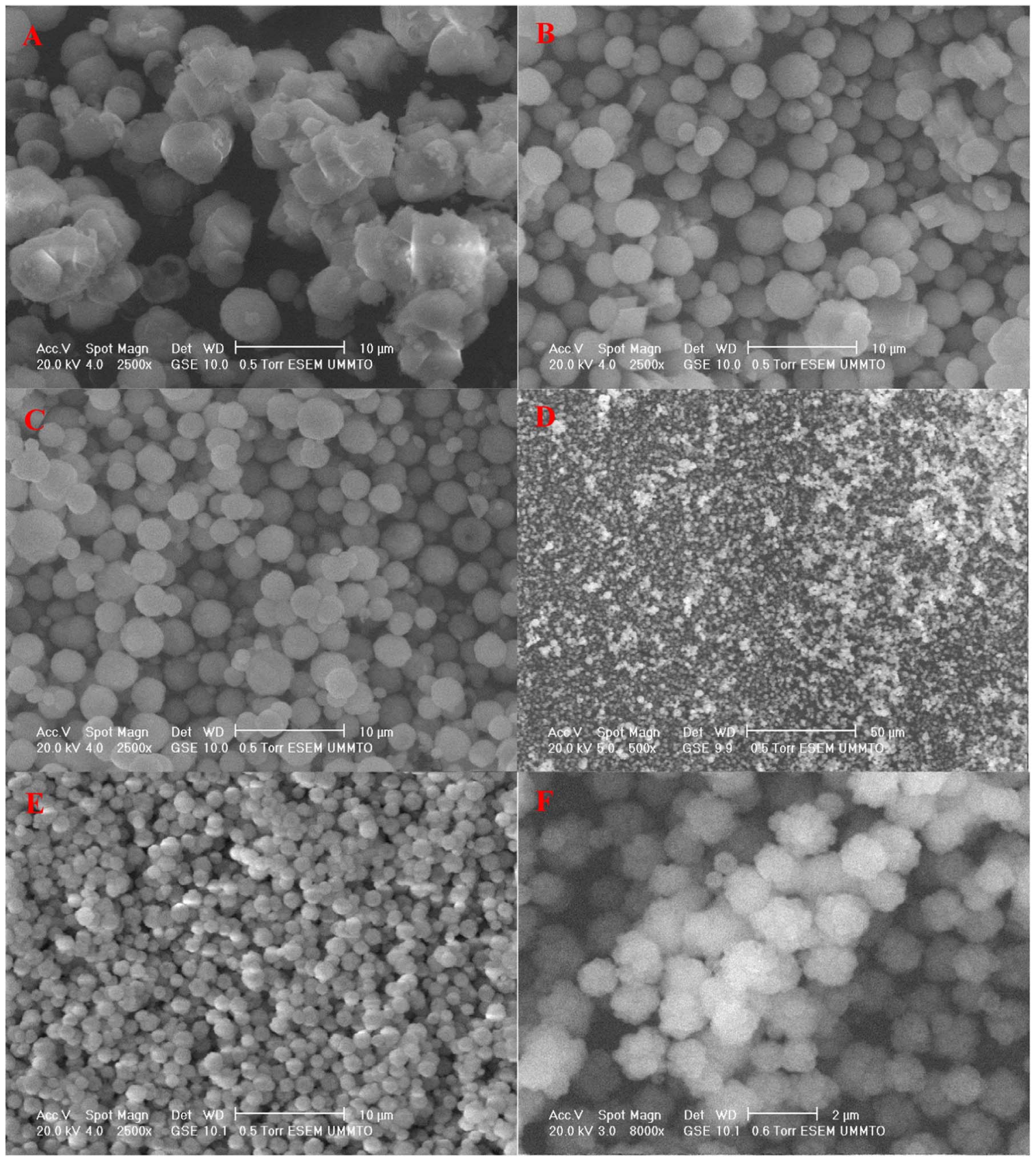

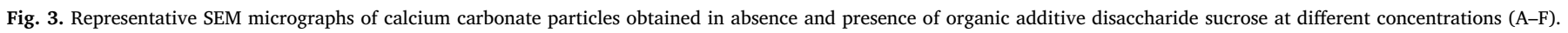

has been not studied until the present research as an additive in the synthesis of vaterite by precipitation. It is remarkable that Yao et al. [16] reported a selection of SEM images of highly monodisperse vaterite microspheres and the shape variations produced under the influence of water and DMF. Ahmed and Ganguli [37] under other experimental conditions, after increasing the concentration of $\mathrm{Ca}^{2+}$ and $\mathrm{CO}_{3}{ }^{2-}$ at $9.375 \mathrm{mM}$ without sucrose and setting the temperature to $20^{\circ} \mathrm{C}$, found that the temperature and the ion concentration is essential to obtain pure vaterite phase. These authors [37] observed by SEM several morphologies of vaterite crystals with controlled growth: nanocrystalline rods, hexagonal plates and spherical particles. However, Zhan et al. [41] synthesized vaterite particles and observed by SEM hexagonal prism morphology. Han et al. [42] using the bubbling method $\left(\mathrm{CO}_{2} / \mathrm{N}_{2}\right.$ mixed gas and $\mathrm{CaCl}_{2}$ solution) and studying the influence of preparation conditions, reported by SEM the formation of spherical vaterite particles at $25^{\circ} \mathrm{C}$, although rhombic particles of calcite increase as increasing the initial concentration of $\mathrm{CaCl}_{2}$.

Zhao et al. [30] observed by SEM hollow vaterite microspheres in the $\mathrm{H}_{2} \mathrm{O} / \mathrm{EG}$ system. They proposed a mechanism based on vaterite nanograins formed at the beginning of the reaction by nucleation and growth. These nanograins aggregate to form a shell and finally the hollow vaterite microspheres are obtained. Their study [39] provides promising results for the elaboration of a biocompatible material for therapeutic applications with encapsulation of bioactive molecules $[6,19]$. Nanoaggregation is the same mechanism of vaterite formation proposed by Trushina et al. [6] Nano-sized grains, as mixtures of vaterite and calcite, have been also reported by Yang et al. [5] However, Andreassen [23] claimed that spherical and polycrystalline particles of vaterite precipitated form solution grow by crystal growth of spherulitic type and not by aggregation of nano-sized precursor crystals. This author observed by SEM cauliflower-like particles of vaterite at $40{ }^{\circ} \mathrm{C}$ and $50{ }^{\circ} \mathrm{C}$ formed from spherical vaterite particles initially obtained at 
$25^{\circ} \mathrm{C}$. Trushina et al. [6] reported by SEM several images of calcium carbonate vaterite crystals of different shapes: flower-like particles, rosette-shaped, hexagonal-shaped, lens and plate shape, being the shape a crucial parameter for practical applications. In a review paper [19] it has been reported the different shapes that can be exhibited by vaterite $\mathrm{CaCO}_{3}$ : monodispersed spheres, thin pancake, lens, hollow spheres, platelet like, wool sphere-like and others. Finally, according to Boyjoo et al. [19] biomolecules, such as polysaccharide, cellulose and soluble starch favour the formation of porous vaterite but at low additive concentrations.

The high relative solubility of vaterite in water accelerates the phenomenon of their transformation into thermodynamically more stable and less soluble calcite [9]. This explains in the present case the prevalence of calcite in the aqueous solution without sucrose (Table 2). The use of this additive to generate a control over the precipitation of calcium carbonate by changing the charges of the particles relies on the capacity of the disaccharide to binding $\mathrm{Ca}^{2+}$ ions. The Calcium saccharate initially formed is able to absorb on specific planes of the crystals, modifying their growth and morphology. In this sense, Kitamura [28] reported that this transition may be influenced by the presence of organic or inorganic macromolecules in solution, caused by adsorption of these species to the solid-liquid interface and subsequently modifying the crystal surface energy.

The probable mechanism at the basis of a sucrose-promoted reversal of the balance in favour of vaterite precipitation is probably related to the fact that the high affinity of $\mathrm{CO}_{3}{ }^{2-}$ towards free $\mathrm{Ca}^{2+}$ is someway decreases when $\mathrm{Ca}^{2+}$ is in form of Calcium saccharate salt, originated by reaction of sucrose and $\mathrm{Ca}^{2+}$ [43]. Once the first sprouts of $\mathrm{CaCO}_{3}$ are formed in the intermolecular spaces of the disaccharide, the hydrophilicity of the disaccharide leads to massive formation of hydrogen bonds between the sugar $\mathrm{OH}$ groups and the $\mathrm{H}_{2} \mathrm{O}$ molecules [44]. At high sucrose concentration, these interactions impoverish the environment of free $\mathrm{H}_{2} \mathrm{O}$ molecules. Under these conditions, $\mathrm{CaCO}_{3}$ crystals formed initially cannot dissolve and the crystallization of vaterite continues by aggregation of preformed nanocrystals to lead to irregular, spherulitic particles of medium size $800 \mathrm{~nm}$ according to the present SEM study (Fig. 3). This morphology can be interpreted assuming that the crystallization takes place in the intermolecular spaces of the organic additive, which prevent the complete growth of the vaterite in spherical or spherulitic forms and leaves large grooves in the sites where they are located. Then, the growth is moving towards the area that is not occupied by the sugar molecules.

The present results strongly suggest that established and stabilized vaterite cores are confined between sucrose molecules, which limits their solubilisation due to a drying effect of the sugar. As a consequence, there is no transformation of vaterite into calcite. At the same time, the presence of sucrose in the medium at high concentrations creates a highly viscous and dense medium that limits the available space for vaterite cores to grow, affording the non-uniform particles and irregular contourns with large groove. They are the result of steric constrain imposed by the sugar molecules when present at high concentrations. This is the same phenomenon observed by $\mathrm{Fu}$ et al. [26] in vaterite particles formed in the presence of EG and cellulose with high energy hydrogen bonds. Zhan et al. [41] performed an early study on biomimetic formation of porous single-crystalline $\mathrm{CaCO}_{3}$ via nanocrystal aggregation. Hexagonal particles of vaterite with intracrystalline gelatin (a denaturated protein with a high molecular weight) were obtained from a hydrothermal reaction $\left(100{ }^{\circ} \mathrm{C}\right.$ for $\left.24 \mathrm{~h}\right)$ between calcium nitrate and urea in the presence of lime-cured gelatin. In the absence of gelatin, only calcite was obtained. Thus, the additive seems to play an important role in stabilizing the metastable vaterite, in a similar way as in this research. Moreover, the high viscosity of the reaction medium using gelatin, [41] as in the present case using high-concentration of sucrose, may be a factor for vaterite formation. In fact, Zhan et al. [41] reported a morphological change, observed by SEM, of the secondary vaterite particles from hexagonal prisms to microspheres and when there is an increase in the gelatin to calcium carbonate ratio with a selforientation of the nanocrystals.

In the present research, in the absence of sucrose or in low sucrose concentration (Table 2), the aqueous medium is very rich in water molecules despite their interactions with this sugar. Under these aqueous conditions, vaterite crystals formed (which has a higher solubility than calcite and aragonite in water) are easily transformed into more stable calcite to reach the threshold of $80 \%$ of the polymorph and more. Increasing the proportion of sucrose, the number of molecules of free water is gradually reduced and, therefore, the effect on the transition process of vaterite to calcite is diminished, thus promoting the stability of the crystalline vaterite phase. Future studies will be addressed to the preparation of promising biomaterials [45] from these synthesized vaterite particles using sucrose.

\section{Conclusions}

In summary, this research reported a novel method to synthesize crystals of pure vaterite as stable nanoparticles and submicron-sized by a simple and relatively rapid synthesis procedure based on chemical precipitation of inorganic salt precursors, calcium nitrate tetrahydrate and sodium bicarbonate, and using sucrose as an additive added in aqueous medium. The increase in sugar concentration promoted the crystal precipitation of vaterite and changed the surface of the precipitated particles of spherical shape. There is a significant difference between $\mathrm{CaCO}_{3}$ precipitation in the absence and presence of sucrose: indeed at $0 \%$ of sucrose, $83 \%$ of calcite was obtained as identified and determined by XRD methods. In contrast, by addition of $67 \%$ of sucrose in aqueous medium, XRD showed only reflections corresponding to $100 \%$ vaterite. A mechanism to rationalize the formation of stable vaterite nanoparticles in this inorganic system using sucrose was proposed based on the interaction of $\mathrm{OH}$ groups with $\mathrm{Ca}^{2+}$ and water molecules. Finally, it is emphasized that the present results may be useful to provide a quick and simple novel method for the controlled synthesis of new advanced biomaterials based on vaterite particles, being the subject of future research now in progress.

\section{Acknowledgements}

This work was supported by the Regional Government, Junta de Andalucía (CICE/TEP/2014) and the special funding support from the Research Group TEP 204 (TEP-204-2014). The authors also thank the critical reading of a first draft of this paper and useful comments provided by Research Professor J.M. García-Fernández of the Institute of Chemical Investigations, CSIC-University of Sevilla.

\section{References}

[1] L. Addadi, S. Raz, S. Weiner, Taking advantage of disorder: amorphous calcium carbonate and its roles in biomineralization, Adv. Mater. 15 (2003) 959-970.

[2] D. Braga, From amorphous to crystalline by design; bio-Inspired fabrication of large micropatterned single crystals, Angew. Chem. Int. 42 (2003) 5544-5546.

[3] P.K. Ajikumar, L.G. Wong, G. Subramanyam, R. Lakshmirayanaran, S. Valiyaveettil, Synthesis and characterization of monodispersed spheres of amorphous calcium carbonate and calcite spherules, Cryst. Growth Des. 5 (2005) 1129-1134.

[4] L. Addadi, D. Joester, F. Nudelman, S. Weiner, Mollusk shell formation: a source of new concepts for understanding biomineralization process, Chem. Eur. J. 12 (2006) 980-987.

[5] X. Yang, G. Xu, Y. Chen, F. Wang, H. Mao, W. Sui, Y. Bai, H. Gong, $\mathrm{CaCO}_{3}$ crystallization control by poly(ethylene oxide)-poly(propylene oxide)-poly(ethylene oxide) triblock copolymer and $O$-(hydroxyl isopropyl) chitosan, J. Cryst. Growth 311 (2009) 4558-4569.

[6] D.B. Trushina, T.V. Bukreeva, M.V. Kovalchuk, M.N. Antipina, $\mathrm{CaCO}_{3}$ vaterite microparticles for biomedical and personal care application, Mater. Sci. Eng. C 45 (2014) 644-658.

[7] Y. Politi, T. Arad, E. Klein, S. Weiner, L. Addadi, Sea urchin spine calcite forms via a transient amorphous calcium carbonate phase, Science 306 (2004) 1161-1164.

[8] N. Nassif, N. Pinna, N. Gehrke, M. Antonietti, C. Jäger, H. Cölfen, Amorphous layer around aragonite platelets in nacre, Proc. Natl. Acad. Sci. USA 102 (2005) 12653-12655.

[9] T. Ogino, T. Suzuki, K. Sawada, The formation and transformation mechanism of 
calcium carbonate in water, Geochim. Cosmochim. Acta 51 (1987) 2757-2767.

[10] G. Falini, S. Fermani, S. Vanzo, M. Miletic, G. Zaffino, Influence on the formation of aragonite or vaterite by otolith macromolecules, Eur. J. Inorg. Chem. 2005 (2005) $162-167$

[11] R. Demichelis, P. Raiteri, J.D. Gale, R. Dovesi, A new structural model for disorder in vaterite from first-principles calculations, Cryst. Eng. Commun. 14 (2012) 44-47.

[12] M. Sato, S. Matsuda, Structure of vaterite and infrared spectra, Z. Krist. 129 (1969) 405-410.

[13] W.F. Cole, B. Kroone, Carbon dioxide in hydrated Portland cement, J. Am. Concr. Inst. 31 (1960) 1275-1296.

[14] G.M. Friedman, D.J. Schultz, Precipitation of vaterite (CaCO3) during oilfield drilling, Miner. Mag. 58 (1994) 401-408.

[15] E.T. Stepkowska, J.L. Pérez-Rodríguez, M.J. Sayagués, J.M. Martínez-Blanes, Calcite, vaterite and aragonite forming on cement hydration from liquid and gaseous phase, J. Therm. Anal. Calorim. 73 (2003) 247-269.

[16] H.B. Yao, J. Ge, L.B. Mao, Y.X. Yan, S.H. Yu, Artificial carbonate nanocrystals and layered structural nanocomposites inspired by nacre: synthesis, fabrication and applications, Adv. Mater. 26 (2014) 163-188.

[17] K. Naka, Y. Tanaka, Y. Chujo, Effect of anionic starbust dendrimers on the crystallization of $\mathrm{CaCO}_{3}$ in aqueous solution: size control of spherical vaterite particles, Langmuir 18 (2002) 3655-3658.

[18] S. Kirboga, M. Öner, Application of experimental design for the precipitation of calcium carbonate in the presence of biopolymer, Powder Technol. 249 (2013) 95-104.

[19] Y. Boyjoo, V.K. Pareek, J. Liu, Synthesis of micro and nano-sized calcium carbonate particles and their applications, J. Mater. Chem. A 2 (2014) 14270-14288.

[20] D.V. Volodkin, N.I. Larionova, G.B. Sukhorukov, Protein encapsulation via porous $\mathrm{CaCO}_{3}$ microparticles templating, Biomacromolecules 5 (2004) 1962-1972.

[21] V.D. Volodkin, A.I. Petrov, M. Prevot, G.B. Sukhorukov, Matrix polyelectrolyte microcapsules: new system for macromolecule encapsulation, Langmuir 20 (2004) 3398-3406.

[22] A. Obata, T. Hotta, T. Wakita, T. Ota, T. Kasuga, Electrospun microfiber meses of silicon-doped vaterite/poly(lactic acid) hybrid for guided bone regeneration, Acta Biomater. 6 (2010) 1248-1257.

[23] J.P. Andreassen, Formation mechanism and morphology in precipitation of vateritenano-aggregation or crystal growth? J. Cryst. Growth 274 (2005) 256-264.

[24] Y. Mori, T. Enomae, A. Isogai, Preparation of pure vaterite by simple mechanical mixing of two aqueous salt solutions, Mater. Sci. Eng. C 29 (2009) 1409-1414.

[25] Y. Kojima, K. Yamaguchi, N. Nishimiya, Effect of amplitude and frequency of ultrasonic irradiation on morphological characteristics control of calcium carbonate, Ultrason. Sonochem. 17 (2010) 617-620.

[26] L.H. Fu, Y.Y. Dong, M.G. Ma, W. Yue, S.L. Sun, R.C. Sun, Why to synthesize vaterite polymorph of calcium carbonate on the cellulose matrix via sonochemistry process? Ultrason. Sonochem. 20 (2013) 1188-1193.

[27] S. Kirboga, M. Öner, E. Akyol, The effect of ultrasonication on calcium carbonate crystallization in the presence of biopolymer, J. Cryst. Growth 401 (2014) 266-270.

28] M. Kitamura, Strategy for control of crystallization of polymorphs, Cryst. Eng. Comm. 11 (2009) 949-964.

[29] J. Wang, Q. Cheng, Z. Tang, Layered nanocomposites inspired by the structure and mechanical properties of nacre, Chem. Soc. Rev. 41 (2012) 1111-1129.

[30] D. Zhao, J. Jiang, J. Xu, L. Yang, T. Song, P. Zhang, Synthesis of template-free hollow vaterite $\mathrm{CaCO}_{3}$ microspheres in the $\mathrm{H}_{2} \mathrm{O}$ /EG system, Mater. Lett. 104 (2013) 28-30.

[31] T. Schüler, W. Tremel, Versatile wet-chemical synthesis of non-agglomerated $\mathrm{CaCO}_{3}$ vaterite nanoparticles, Chem. Commun. 47 (2011) 5208-5210.

[32] B.V. Parakhonskiy, A. Haase, R. Antolini, Sub-micrometer vaterite containers: synthesis, substance loading and release, Angew. Chem. Int. Ed. 51 (2012) 1195-1197.

[33] C.L. Yao, W.H. Xu, A.M. Ding, J.M. Zhu, Sucrose/bovine serum albumin mediated biomimetic crystallization of calcium carbonate, J. Chem. Sci. 121 (2009) 89-93.

[34] F. Takabait, L. Mahtout, L. Pérez-Villarejo, B. Carrasco-Hurtado, P.J. Sánchez-Soto, Obtención de nanopartículas de carbonato de calcio a partir de precursores inorgánicos y sacarosa como aditivo con potencial utilización como biomaterial, Bol. Soc. Esp. Ceram. V. 55 (2016) 179-184.

[35] C.G. Kontoyannis, N.V. Vagenas, Calcium carbonate phase analysis using XRD and FT-Raman spectroscopy, Analyst 125 (2000) 251-255.

[36] N.V. Vagenas, A. Gatsouli, C.G. Kontoyannis, Quantitative analysis of synthetic calcium carbonate polymorphs using FT-IR spectroscopy, Talanta 59 (2003) 831-836.

[37] J. Ahmed, A.K. Ganguli, Controlled growth of nanocrystalline rods, hexagona plates and spherical particles of the vaterite form of calcium carbonate, Cryst. Eng. Commun. 11 (2009) 927-932.

[38] L. Dupont, F. Portemer, M. Figlarz, Synthesis and study of well crystallized $\mathrm{CaCO}_{3}$ vaterite showing a new habitus, J. Mater. Chem. 7 (1997) 797-800.

[39] Y. Fan, R. Wang, Submicrometer-sized vaterite tubes formed through nanobubbletemplated crystal growth, Adv. Mater. 17 (2005) 2384-2388.

[40] F. Zhang, X. Yang, F. Tian, Calcium carbonate growth in the presence of water cellulose ethers, Mater. Sci. Eng. C 29 (2009) 2530-2538.

[41] J. Zhan, H.P. Lin, C.Y. Mou, Biomimetic formation of porous single-crystalline CaCO3 via nanocrystal aggregation, Adv. Mater. 15 (2003) 621-623.

[42] Y.S. Han, G. Hadiko, M. Fuji, M. Takahashi, Factors affecting the phase and morphology of CaCO3 prepared by a bubbling method, J. Eur. Ceram. Soc. 26 (2006) 843-847.

[43] N. Roy, A.K. Mitra, Fundamental studies on the interaction of alkaline-earth metals with carbohydrates: II. Behavior of some disaccharides towards the hydroxides of barium, calcium, and strontium, Carbohyd. Res. 24 (1972) 180-183.

[44] T. Suzuki, The hydration of glucose: the local configurations in sugar-water hydrogen bonds, Phys. Chem. Chem. Phys. 10 (2008) 96-105.

[45] S. Kim, C.B. Park, Mussel-inspired transformation of $\mathrm{CaCO}_{3}$ to bone minerals, Biomaterials 31 (2010) 6628-6634. 